Frigate birds track atmospheric conditions over months-Iong transoceanic flights

Weimerskirch, Henri; Bishop, Charles; Jeanniard-du-Dot, Tiphaine; Prudor, Aurélien ; Sachs, Gottfried

\title{
Science
}

DOI:

10.1126/science.aaf4374

Published: 31/07/2016

Peer reviewed version

Cyswllt i'r cyhoeddiad / Link to publication

Dyfyniad o'r fersiwn a gyhoeddwyd / Citation for published version (APA):

Weimerskirch, H., Bishop, C., Jeanniard-du-Dot, T., Prudor, A., \& Sachs, G. (2016). Frigate birds track atmospheric conditions over months-long transoceanic flights. Science, 353(6294), 74-78. https://doi.org/10.1126/science.aaf4374

\footnotetext{
Hawliau Cyffredinol / General rights

Copyright and moral rights for the publications made accessible in the public portal are retained by the authors and/or other copyright owners and it is a condition of accessing publications that users recognise and abide by the legal requirements associated with these rights.

- Users may download and print one copy of any publication from the public portal for the purpose of private study or research.

- You may not further distribute the material or use it for any profit-making activity or commercial gain

- You may freely distribute the URL identifying the publication in the public portal ?
}

Take down policy

If you believe that this document breaches copyright please contact us providing details, and we will remove access to the work immediately and investigate your claim. 


\section{Frigate birds track atmospheric conditions over months-long transoceanic flights}

1. Henri Weimerskirch

2. Charles Bishop

3. Tiphaine Jeanniard-du-Dot

4. Aurélien Prudor

5. Gottfried Sachs

\section{Abstract}

Understanding how animals respond to atmospheric conditions across space is critical for understanding the evolution of flight strategies and long-distance migrations. We studied the three-dimensional movements and energetics of great frigate birds (Fregata minor) and showed that they can stay aloft for months during transoceanic flights. To do this, birds track the edge of the doldrums to take advantage of favorable winds and strong convection. Locally, they use a roller-coaster flight, relying on thermals and wind to soar within a 50- to 600-meter altitude band under cumulus clouds and then glide over kilometers at low energy costs. To deal with the local scarcity of clouds and gain longer gliding distances, birds regularly soar inside cumulus clouds to use their strong updraft, and they can reach altitudes of 4000 meters, where freezing conditions occur.

The movement of animals is driven by processes that act across multiple spatial and temporal scales. Long-distance movements such as the migrations of birds have evolved in response to large-scale environmental gradients ( 1 ). In particular, atmospheric conditions play a large role in determining the efficiency of migratory routes, whose consistency over years has allowed evolutionary processes to act at population levels (2). At smaller time and spatial scales, longrange movements have to constantly be adjusted to local conditions, in particular to minimize energy expenditure $(\underline{3}, \underline{4})$. These long movements or migrations can be done over inhospitable areas as different as deserts, high mountains, or oceans, which come with specific environmental constraints to which birds need to behaviorally and physiologically adapt their flight strategies $(\underline{5}, \underline{6})$. How these long restless flights can be energetically achieved has attracted much interest, but remains largely unknown because of the inherent difficulties of studying such behaviors in situ.

Biologists have long been attracted to locomotor extremes because they provide clear examples from which information about structure-function relationships can be drawn (7). Among birds, frigate birds are extreme in many aspects of their life history, including having the lowest wing loading, with a specialized capacity for soaring flight $(\underline{8})$. They are also unusual seabirds because their feathers are not waterproof and their legs are small, so they are unable to land on the sea surface even though they feed exclusively at sea. They deal with these conflicting constraints by staying aloft for days when they are foraging from their nest when breeding (9). Probably as a consequence of these extreme attributes, frigate birds have the longest period of parental care in birds, suggesting a long period of learning to acquire flight and foraging abilities in early life (10). Their ability to remain airborne continuously for days is probably possible because of the capability of frigate birds to use thermals over the sea as a main energy source for soaring $(\underline{11}, \underline{12})$. 
We asked how frigate birds can perform long migrations over oceans without landing and whether oceanic thermals are reliable enough in space and time to allow birds to stay airborne over long periods. To address these questions, we investigated the movement of frigate birds at several spatial scales with regard to (i) how frigate birds make use of large-scale weather systems to perform long-range movements, and (ii) how flight dynamics and energetics at a finer scale contribute to these long ranges.

We studied the three-dimensional movements and energetics of frigate birds on Europa Island (Fig. 1) between 2011 and 2015 (프). To study large-scale migratory movements, 24 adults and 25 juvenile birds were equipped with solar-powered Argos transmitters (13). To study the relationship between heart rate, activity (flapping frequency), and behavior (ascent rates and horizontal speed), 11 adult females were equipped with external custom-designed loggers measuring triaxial acceleration and electrocardiography and a Global Positioning System (GPS) device (13). To study movements, activity, and ambient temperature, 37 adult females and males were equipped with solar-powered GPS accelerometers, whose data were recovered regularly by an automatic recording station (13).
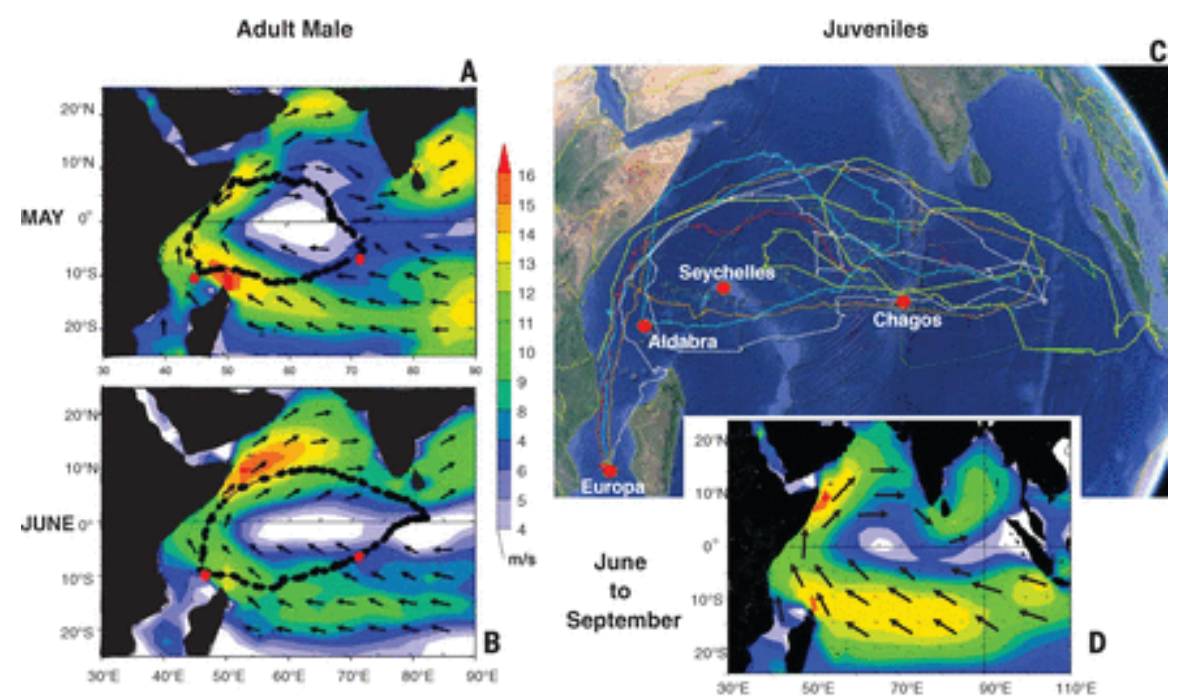

Fig. 1 Movements of adult and juvenile frigate birds in relation to wind conditions in the Indian Ocean.

(Left) Two successive clockwise movements from Aldabra Island (Seychelles) of an adult male great frigate bird (no. 138502) in relation to wind strength (in meters per second, color scale) and direction (arrows). (A) In May 2015, a 24-day foraging trip around the doldrums (shown by the absence of wind, in white), with 1 day of rest in Chagos. (B) In June 2015, a 28-day foraging trip, with a 36-hour rest in Chagos. (C) Movements between June and September 2015 of six young frigate birds fledged from Europa Island, moving around the doldrums zone. (D) Climatology of wind speed and direction (average values over 4 months) in June to September 2015, showing the average position of the doldrums (white) on the equator.

During the southwest Indian monsoon from June to October, strong trade winds occur in the southern Indian Ocean and cross the equator to form southwest winds in the northern Indian Ocean (14) (Fig. 1). During this season, adult frigate birds finishing the breeding season left Europa and migrated northward to take advantage of the southerly winds. They settled on roosting sites in the Seychelles from where they foraged for months. Some adults performed long looping movements around the equator, where a belt of converging air and wind occurs, with no wind in the center, named the doldrums zone by ancient mariners (Fig. 1). On 
successive loops, adults closely followed the edges of the doldrums, which oscillate longitudinally (Fig. 1, A and B). Birds stayed continuously on the wing for periods lasting up to 48 days and traveled on average $420 \pm 220 \mathrm{~km}$ daily.

Young frigate birds left their birthplace at the same time as adults, but independently of their parents. They crossed the equator and turned eastward to enter into a circular transoceanic movement into the wind belt around the doldrums (Fig. 1, C and D). During these dispersive movements, juvenile birds stayed continuously aloft for flights lasting up to 2.1 months (average maximum time spent aloft, $41.2 \pm 15.1$ days, $n=8$ birds). They travelled on average $450 \pm 220 \mathrm{~km}$ daily. They episodically stopped on isolated islands such as Chagos, islets off Indonesia, or on islets of the Seychelles archipelago for very short rests ( 8 to 48 hours) before continuing their large-scale wandering movement tracking the edge of the doldrums (Fig. 1C and fig. S1). They flew at altitudes ranging between the sea surface and $3000 \mathrm{~m}$, but mainly between 0 and $600 \mathrm{~m}$ (fig. S2).

To understand how frigate birds are able to stay aloft for such long periods, we studied their flight dynamics and energetics during 2- to 15-day foraging trips from Europa. Breeding frigate birds travelled on average $410 \pm 142 \mathrm{~km}$ per day ( $n=18$ birds), mainly during the daytime, traveling over shorter distances at night (Fig. 2). Two clear behavioral modes were identified during movements at sea. Traveling occurred with high ground speeds and low wing beat frequencies ( $82 \pm 9 \%$ of travelling time with no or rare wing beats), with birds remaining at altitudes ranging from 30 to $2000 \mathrm{~m}$, reaching up to $4120 \mathrm{~m}$. Foraging can only occur when birds descend close to the sea surface (altitudes 0 to $30 \mathrm{~m}$ ), and during these periods they are very active, flapping during $75 \pm 18 \%$ of the foraging phase (Fig. 2). Active foraging occurred only episodically ( $10 \pm 7 \%$ of time at sea), indicating rare feeding opportunities, mainly during the day ( $86.4 \%$ of bouts of active foraging occurred during the daytime). 


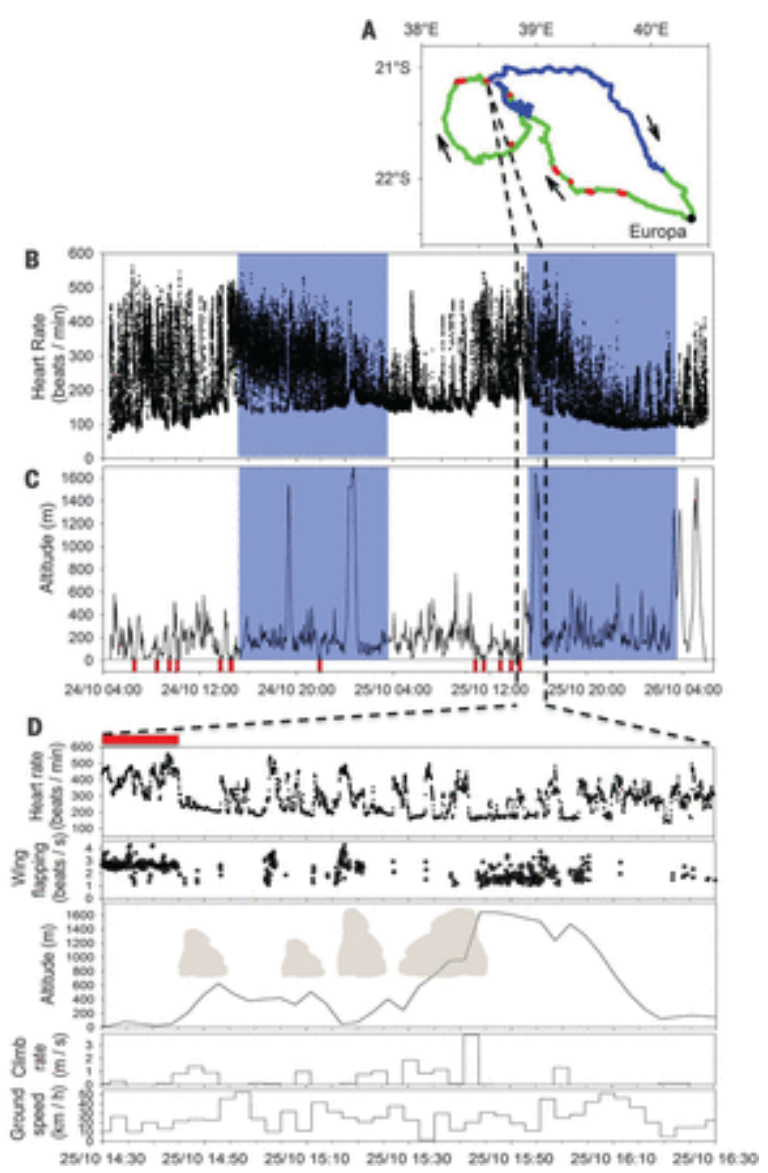

Fig. 2 Movement, changes in altitude, heart rate, and flight parameters during a 2-day trip at sea.

(A) 1130-km-long movement from Europa during the daytime (green) and night (blue) with foraging bouts in red, with recorded $(\mathbf{B})$ heart rate and $(\mathbf{C})$ altitude. Shaded blue areas represent nighttime, and red blocks represent foraging bouts. (D) A 2-hour period during the trip at sea, with an active foraging phase followed by a traveling phase, showing the changes in altitude and corresponding heart rate, wing-flapping rate, climb rate, and ground speed. On the altitude panel, the predicted presence of cumulus clouds is indicated (gray).

When in flight at sea, heart rate was on average $203 \pm 84$ beats $\min ^{-1}$ but varied extensively (Fig. 2 and figs. S3 and S4), occasionally attaining values as low as when resting on the nest $\left(71 \pm 25\right.$ beats $\mathrm{min}^{-1}$, range 57 to 215$)$. Heart rate and dynamic body acceleration were generally well correlated ( $\underline{13}$ ) (figs. S3 and S4); therefore, we used dynamic body acceleration, measured on all individuals, as the main proxy for energy expenditure. Whereas active foraging is very costly for frigate birds, requiring high dynamic body acceleration and heart rates, traveling periods have a remarkably low energy expenditure, with few wingbeats (Fig. 2 and fig. S3), suggesting that overall field metabolic rate during months at sea is likely to be exceptionally low (13) (figs. S5 and S6). Excluding periods of active foraging close to the surface, dynamic body acceleration was the lowest at altitudes between 300 and $600 \mathrm{~m}$ (fig. S7), indicating an optimal altitude for traveling at low cost.

Traveling at low cost is achieved by successive climbs, mainly through soaring with no or few wing flaps and low heart rate, and descents, by gliding (Figs. 2 and $\underline{3}$ ). A close examination of flight paths shows that when soaring, birds move with the wind (fig. S8), using circling movements to soar (Fig. 3C) in thermals below cumulus clouds where rising air creates updrafts 
(15). Because of the strong trade winds, they drift with the wind while climbing (Fig. 3), resulting in "wind-drift circling soaring." Conversely, when gliding, they preferentially fly with side winds and achieve the highest ground speeds (Figs. 2 and $\underline{3}$ and fig. S8). The resulting movement is a complex zig-zagging, roller-coaster movement, with an average altitude xgain of $59.1 \pm 43.8 \mathrm{~m}$ per kilometer covered (ground distance); i.e., $15.4 \pm 3.0 \mathrm{~km}$ climbed daily. These vertical movements take place generally up to 600 to $700 \mathrm{~m}$, corresponding to the base of the cumulus clouds that is relatively constant throughout the trade wind zone ( $\underline{16})$.

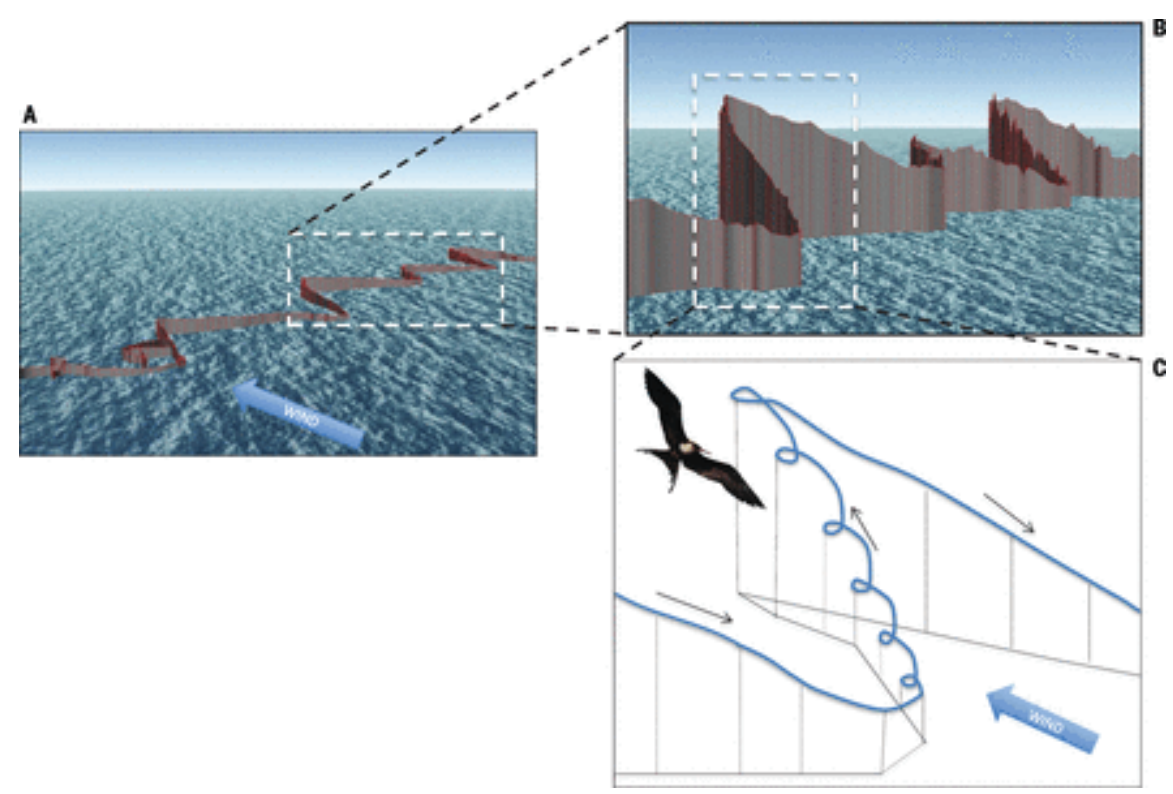

Fig. 3 Three-dimensional movement of a frigate bird at three scales.

(A) Section of a track of a frigate bird traveling with side winds. (B) Enlargement showing the movement alternating gliding and soaring, resulting in a zig-zag and roller-coaster movement. (C) Detailed schematic representation of a single cycle of soaring and gliding, illustrating the climb by circling, with a resulting drift due to wind, followed by the descent.

However, birds regularly climbed up to 1000 to $2000 \mathrm{~m}$, with a maximum of $4120 \mathrm{~m}$ (fig. S9). The frequency of climbs at altitudes higher than $700 \mathrm{~m}$ increased throughout the day to peak during the first hours of night (fig. S10). Climbing to high altitudes can be separated into a phase of slow climb up to the base of the cumulus clouds at 600 to $700 \mathrm{~m}$, followed by a more rapid climb to $1600 \mathrm{~m}$ (Fig. 2D) or higher. This second phase of the ascent is performed without flapping the wings (Fig. 2D); i.e., in pure soaring flight and with climb rates reaching 4 to $5 \mathrm{~m}$ $\mathrm{s}^{-1}$ at 2000 to $3000 \mathrm{~m}$ (fig. S11). Ascent to high altitude can only take place inside cumulus clouds, where updrafts reach $5 \mathrm{~m} \mathrm{~s}^{-1}$ and are strong enough to provide such climb rates (15). During the gliding phase made outside the clouds, the minimum sink rate was $23.6 \pm 19.1 \mathrm{~m}$ of ground distance covered per meter lost between 500- to 700-m altitudes, compared to 14.3 $\pm 11.7 \mathrm{~m}$ at higher altitudes $\left(F_{1,7}=8.4, P=0.045\right)$.

Our study shows that frigate birds can remain almost indefinitely on the wing by tracking, at a basin-wide scale, the wind belt around the doldrums, an atmospheric feature whose location is predictable. Locally, they display a specific flight strategy based on an energy-efficient use of convection and wind. By using wind-drift circling soaring and long periods of gliding, frigate birds are able to simultaneously use convection and wind as energy sources and move over extensive distances at low energy costs. They favor altitudes between 50 and $600 \mathrm{~m}$, where atmospheric conditions are optimal for low-cost flight; i.e., steady winds and updrafts from 
convection under clouds (Fig. 4). These altitudes are also convenient to spot feeding opportunities from long distances away during the daytime; birds then descend close to the surface to forage actively when feeding opportunities have been detected ( $\underline{9})$.

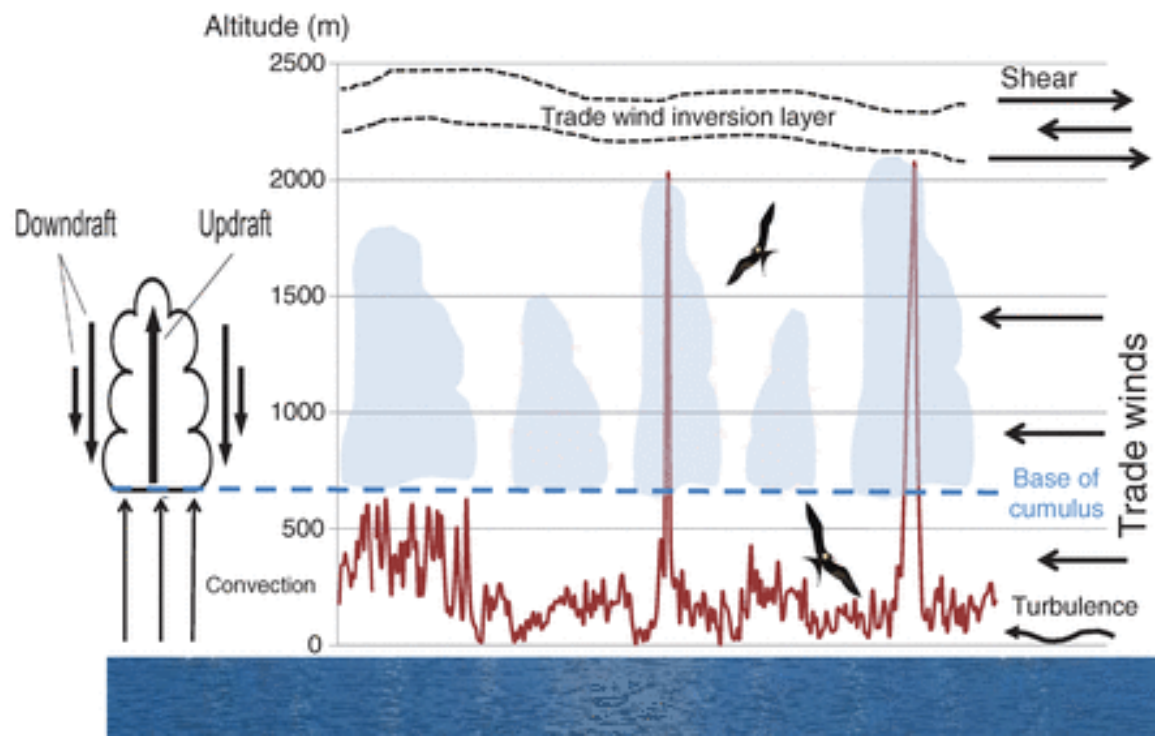

Fig. 4 Altitudinal movement of a frigate bird in relation to potential atmospheric conditions.

The traveling flight is performed between 30 and 600 to $700 \mathrm{~m}$ altitude in a band with regular winds, avoiding the turbulence close to the surface. The bird occasionally climbs to $2000 \mathrm{~m}$ within cumulus clouds that form by convection, whose base is at 600 to $700 \mathrm{~m}$ and whose vertical extension is limited by the inversion layer where strong shear occurs. A schematic presentation of the updrafts and downdrafts characteristic of cumulus clouds is shown at left $(\underline{24})$.

Although birds are not thought to carry out intentional, sustained cloud climbs $(\underline{17}, \underline{18})$, our study shows the ability of frigate birds to frequently ascend to very high altitudes inside clouds. At an altitude of $4000 \mathrm{~m}$, air temperatures are negative and air density and oxygen availability are almost half of those at sea level (17), suggesting that this tropical bird encounters extreme conditions at such altitudes. Cumulus clouds and cloud fields are considered to be randomly distributed in space in the trade wind zone (16). In these conditions, climbing higher than 1000 $\mathrm{m}$ presents a fundamental advantage by allowing frigate birds to cover much longer distances by gliding to reach the next updraft under clouds; for example, $>60 \mathrm{~km}$ of glide from $4000 \mathrm{~m}$ as compared to $17 \mathrm{~km}$ when starting a glide just at the base of cumulus clouds. Therefore, when clouds are sparsely distributed, birds can adjust their gliding distance by climbing higher to avoid the risk of switching to costly flapping flight. Juvenile individuals are able to master the flight strategy of adults as soon as they become independent. When they leave their birthplace, they all head north to reach the equator and circle the entire Indian Ocean. This stereotyped movement suggests a genetically encoded behavior that brings young individuals directly to a predictable, favorable, and large-scale atmospheric feature located thousands of kilometers from their birthplace.

Great frigate birds are the only birds other than swifts (19) to be able to stay aloft for months. Long periods in continuous flight are interrupted by very short periods of rest on land, suggesting that frigate birds might sleep while airborne (20). Periods of low activity (no flapping) occur mainly during soaring episodes and may allow sleep. However, periods of completely motionless (no flapping at all) flight, potentially corresponding to periods of sleep, 
are relatively short, ( $2 \mathrm{~min}$, never exceeding $12 \mathrm{~min})$. Animals such as frigate birds may have evolved the ability to dispense with sleep when ecological demands favor wakefulness such as during extended flights $(\underline{21})$, but studies are needed to determine how they sleep during much longer-lasting flights

Frigate birds clearly encounter several atmospheric challenges during their movements at sea, such as low temperatures, low air density and oxygen levels during high climbs, and the unpredictable distribution of cumulus clouds at small scale, together with the presence of powerful cyclones in their optimal range. This dependence on atmospheric systems could make them particularly sensitive to future climate changes, along with some other seabirds (22). Climate models for the tropical ocean forecast an increase in the intensity of tropical storms and of convections around the equator, where the doldrums and strong convections occur (23). More variable atmospheric conditions in the future may become too challenging for a species that already seems to encounter extreme conditions during its lifetime movements.

\section{SUPPLEMENTARY MATERIALS}

www.sciencemag.org/content/353/6294/74/suppl/DC1

Materials and Methods

Supplementary Text

Figs. S1 to S10

Table S1

References $(\underline{25}-\underline{34})$

\section{REFERENCES AND NOTES}

1. G.-R. Walther, E. Post, P. Convey, A. Menzel, C. Parmesan, T. J. Beebee, J. M. Fromentin, O. Hoegh-Guldberg, F. Bairlein, Ecological responses to recent climate change. Nature 416, 389-395 (2002). doi:10.1038/416389a pmid:11919621

2. B. Kranstauber, R. Weinzierl, M. Wikelski, K. Safi, Global aerial flyways allow efficient travelling. Ecol. Lett. 18, 1338-1345 (2015). doi:10.1111/ele.12528 pmid:26477348

3. T. Alerstam, Ã. Lindström, Optimal bird migration: The relative importance of time, energy, and safety, in Bird Migration: Physiology and Ecophysiology, E. Gwinner, Ed. (Springer, 1990), pp. 331-351.

4. J. Rayner, The mechanics of flight and bird migration performance, in Bird Migration: Physiology and Ecophysiology, E. Gwinner, Ed. (Springer, 1990), pp. 283-299.

5. C. M. Bishop, R. J. Spivey, L. A. Hawkes, N. Batbayar, B. Chua, P. B. Frappell, W. K. Milsom, T. Natsagdorj, S. H. Newman, G. R. Scott, J. Y. Takekawa, M. Wikelski, P. J. Butler, The roller coaster flight strategy of bar-headed geese conserves energy during Himalayan migrations. Science 347, 250-254 (2015). doi:10.1126/science.1258732 pmid:25593180 
6. R. E. Gill, T. L. Tibbitts, D. C. Douglas, C. M. Handel, D. M. Mulcahy, J. C. Gottschalck, N. Warnock, B. J. McCaffery, P. F. Battley, T. Piersma, Extreme endurance flights by landbirds crossing the Pacific Ocean: Ecological corridor rather than barrier? Proc. Biol. Sci. 276, 447-457 (2009). pmid:18974033

7. M. H. Dickinson, C. T. Farley, R. J. Full, M. A. Koehl, R. Kram, S. Lehman, How animals move: An integrative view. Science 288, 100-106 (2000). doi:10.1126/science.288.5463.100 pmid:10753108

8. C. Pennycuick, Bird Flight Performance: A Practical Calculation Manual (Oxford Univ. Press, Oxford, 1989).

9. H. Weimerskirch, M. Le Corre, S. Jaquemet, M. Potier, F. Marsac, Foraging strategy of a top predator in tropical waters: Great frigatebirds in the Mozambique Channel. Mar. Ecol. Prog. Ser. 275, 297-308 (2004). doi:10.3354/meps 275297

10. J. B. Nelson, The breeding biology of frigatebirds - a comparative review. The Living Bird 14, 113-155 (1976).

11. C. J. Pennycuick, Thermal soaring compared in three dissimilar tropical bird species, Fregata magnificens, Pelecanus occidentalis and Coragyps atratus. J. Exp. Biol. 102, 307-325 (1983).

12. H. Weimerskirch, O. Chastel, C. Barbraud, O. Tostain, Flight performance: Frigatebirds ride high on thermals. Nature 421, 333-334 (2003). doi:10.1038/421333a pmid:12540890

13. See the supplementary materials on Science Online.

14. A. Laing, J. M. Evans, Introduction to Tropical Meteorology: A Comprehensive Online \& Print Textbook, Comet Program, A. Laing, Ed. (University Corporation for Atmospheric Research, Boulder, CO, 2011).

15. J. S. Malkus, Some results of a trade-cumulus cloud investigation. J. Meteorol. 11, 220-237 (1954). doi:10.1175/1520-0469(1954)011 <0220:SROATC>2.0.CO;2

16. U. Nair, R. Weger, K. Kuo, R. Welch, Clustering, randomness, and regularity in cloud fields: 5. The nature of regular cumulus cloud fields. J. Geophys. Res. Atmos. 103, 11363-11380 (1998).

17. C. J. Pennycuick, Modelling the Flying Bird (Elsevier, 2008).

18. T. Alerstam, D. Christie, A. Ulfstrand, Bird Migration (Cambridge Univ. Press, 1993).

19. F. Liechti, W. Witvliet, R. Weber, E. Bächler, First evidence of a 200-day non-stop flight in a bird. Nat. Commun. 4, 2554 (2013). doi:10.1038/ncomms3554 pmid:24104955

20. N. C. Rattenborg, Do birds sleep in flight? Naturwissenschaften 93, 413-425 (2006). doi:10.1007/s00114-006-0120-3 pmid:16688436

21. J. A. Lesku, N. C. Rattenborg, M. Valcu, A. L. Vyssotski, S. Kuhn, F. Kuemmeth, W. Heidrich, B. Kempenaers, Adaptive sleep loss in polygynous pectoral sandpipers. Science 337, 1654-1658 (2012). pmid:22878501

22. H. Weimerskirch, M. Louzao, S. de Grissac, K. Delord, Changes in wind pattern alter albatross distribution and life-history traits. Science 335, 211-214 (2012). doi:10.1126/science.1210270 pmid:22246774

23. U. C. Mohanty, M. Mohapatra, O. P. Singh, B. K. Bandyopadhyay, L. S. Rathore, Monitoring and Prediction of Tropical Cyclones in the Indian Ocean and Climate Change (Springer, Dordrecht, Netherlands, 2014).

24. H. J. J. Jonker, T. Heus, P. P. Sullivan, A refined view of vertical mass transport by cumulus convection. Geophys. Res. Lett. 35, L07810 (2008). doi:10.1029/2007GL032606 
25. R. J. Spivey, C. M. Bishop, An implantable instrument for studying the long-term flight biology of migratory birds. Rev. Sci. Instrum. 85, 014301 (2014). doi:10.1063/1.4854635 pmid:24517787

26. R. J. Spivey, C. M. Bishop, Interpretation of body-mounted accelerometry in flying animals and estimation of biomechanical power. J. R. Soc. Interface 10, 20130404 (2013). doi:10.1098/rsif.2013.0404 pmid:23883951

27. R. J. Spivey, S. Stansfield, C. M. Bishop, Analysing the intermittent flapping flight of a Manx Shearwater, Puffinus puffinus, and its sporadic use of a wave-meandering wing-sailing flight strategy. Prog. Oceanogr. 125, 62-73 (2014). doi:10.1016/j.pocean.2014.04.005

28. C. M. Bishop, R. J. Spivey, Integration of exercise response and allometric scaling in endotherms. J. Theor. Biol. 323, 11-19 (2013). doi:10.1016/j.jtbi.2013.01.002 pmid:23328533

29. S. Ward, C. M. Bishop, A. J. Woakes, P. J. Butler, Heart rate and the rate of oxygen consumption of flying and walking barnacle geese (Branta leucopsis) and bar-headed geese (Anser indicus). J. Exp. Biol. 205, 3347-3356 (2002). pmid:12324544

30. F. A. Hartman, Locomotor mechanisms of birds. Smithsonian Misc. Collect. 143, 1$91(1961)$.

31. P. S. Enger, Heat regulation and metabolism in some tropical mammals and birds. Acta Physiol. Scand. 40, 161-166 (1957).

32. D. C. Dearborn, A. D. Anders, J. B. Williams, Courtship display by great frigatebirds, Fregata minor: An energetically costly handicap signal? Behav. Ecol. Sociobiol. 58, 397-406 (2005). doi:10.1007/s00265-005-0933-7

33. H. I. Ellis, G. W. Gabrielsen, Energetics of free ranging seabirds, in Biology of Marine Birds, E. A. Schreiber, J. Burger, Eds. (CRC Press, Boca Raton, FL, 2002).

34. C. M. Bishop, Heart mass and the maximum cardiac output of birds and mammals: Implications for estimating the maximum aerobic power input of flying animals.

Philos. Trans. R. Soc. London Ser. B 352, 447-456 (1997). doi:10.1098/rstb.1997.0032

35. Acknowledgments: The tracking data presented in the paper are available from the Dryad Digital Repository. We thank the Forces Armées de la Zone Sud de l'Océan Indien for transport and logistical support on Europa Island and the TAAF Administration for allowing us to work on Europa Island. We thank the fieldworkers involved in the study on Europa, in particular J. B. Pons and R. Weimerskirch; R. Spivey for help with preparing the electrocardiogram and acceleration tags and for the data processing of the heart rate recording; and A. Corbeau for help with data analyses. The study is a contribution to the Program EARLYLIFE funded by a European Research Council Advanced Grant under the European Community's Seven Framework Program FP7/2007-2013 (grant agreement ERC-2012-ADG_20120314 to H.W.). We thank Y. Ropert-Coudert, Y. Cherel, and two anonymous reviewers for helpful comments on earlier versions of the manuscript. 